REVISTA DE DERECHO UNED, NÚM. 24, 2019

\title{
EL DEBER DE NOTIFICAR Y EL DERECHO A LA NO AUTOINCULPACIÓN EN LA PROTECCIÓN DE DATOS PERSONALES
}

\author{
THE OBLIGATION TO NOTIFY AND THE PRIVILEGE AGAINST \\ SELF-INCRIMINATION IN PERSONAL DATA PROTECTION
}

\author{
Carolina Marcela Reyes Kahansky \\ Doctorado en Unión Europea - UNED
}

\begin{abstract}
Resumen: El RGPD establece para todos los responsables y encargados de tratamientos de datos personales la obligación de notificar a la autoridad de protección de datos las violaciones de la seguridad de los datos que están tratando, obligación cuyo incumplimiento puede entrañar una sanción, que se instaura como medida coactiva. En los casos en que la brecha de la seguridad de los datos esté relacionada con un incumplimiento de otras obligaciones que el RGPD pone a cargo del mismo responsable o encargado, la notificación se puede convertir en una declaración autoinculpatoria obtenida bajo coacción. Por ello analizamos en este artículo la posibilidad de invocar la notificación u otras evidencias de incumplimientos que se han conocido por medio de ella, en calidad de prueba de cargo en un procedimiento sancionador seguido contra el responsable.
\end{abstract}

Palabras clave: Datos personales - RGPD - deber de notificar derecho a no autoincriminarse - garantías del proceso administrativo sancionador

Abstract: The GDPR stablishes for all the controllers and processors of personal data, the obligation to notify to the supervisory authority the breaches occurred to the personal data that they process. The infringement of this obligation shall be subject to adminis- 
trative penalties, that are thus set as a coercive measure. If the personal data breach is related to an infringement of other obligations imposed by the GDPR to the same controller or processor, then the notification may become a self-incriminating statement made under coercion. For those reasons, in this article we analyse the possibility of bringing the said notification or other evidence based on it, as incriminatory evidence against the subject on a proceeding for an offence under the GDPR.

Keywords: Personal Data - GDPR - obligation to notify privilege against self-incrimination — privileges in the punitive proceedings

Recepción original: 04/12/2018

Aceptación original: 27/05/2019

Sumario: Introducción. I. La protección de datos personales en el reglamento general de la Unión Europea. A. Garantías y sanciones. B.La obligación de notificación de las brechas de seguridad. C. Autoridades de protección de datos: Facultades y poderes. II. Colisión con el derecho a la no autoinculpación. A. Planteamiento del problema. B. Soluciones en la legislación, la jurisprudencia y la doctrina. 1. En la legislación española. 2. En la jurisprudencia. 3. En la doctrina. C. Aplicación al ámbito administrativo. Conclusiones. Bibliografía.

\section{INTRODUCCIÓN}

El derecho de las personas físicas a la protección frente a la manipulación indebida de sus datos personales es un derecho fundamental de cuarta generación ${ }^{1}$ que actualmente se configura como autónomo, aunque está estrechamente relacionado con la protección de otros derechos tales como la vida privada y familiar, el desarrollo de la propia personalidad, el honor y, en definitiva, con la dignidad de la persona ${ }^{2}$. Con respecto al primero de los mencionados, Rebollo Delgado ha expresado que el derecho a la intimidad se dividiría en dos aspectos: Por un lado, la intimidad «física o clásica» y, por otro, la «intimidad informativa, entendida ésta como el derecho a determinar cómo y en qué medida se puede comunicar a otros, información

${ }^{1}$ GÓMEZ SÁNCHEZ, Y: Constitucionalismo multinivel. Derechos fundamentales. Ed. Sanz y Torres, Madrid, 2015. Págs. 36-44.

2 REBOLLO DELGADO, L: Protección de datos en Europa. Origen, evolución y regulación actual. Ed. Dykinson, Madrid, 2018. Pág. 77. 
sobre uno mismo ${ }^{3}$, siendo ésta última la que salvaguarda la protección de datos personales.

Para garantizar este derecho, es de suma importancia que los individuos tengan control sobre sus datos o sobre la información que sobre ellos circula en la infoesfera ${ }^{4}$, ya que una manipulación malintencionada de los datos personales puede permitir a terceros inmiscuirse en la privacidad del sujeto a quien los datos identifican, por algunos medios como por ejemplo dar publicidad a la información que el individuo quiere reservar para su esfera íntima o que afecta a su honor y su personalidad 5 .

Por todo ello los ordenamientos jurídicos europeo y español aspiran a garantizar a las personas que puedan ejercer control sobre las operaciones a que son sometidos sus datos personales, para evitar su manipulación indebida o no autorizada, asegurando así también la protección de los otros derechos fundamentales citados. Lo que a nivel de la Unión Europea se logra, con mayor o menor acierto ${ }^{6}$, a través del reconocimiento del derecho de los individuos a la protección de sus datos personales en el artículo 8 de la Carta de Derechos Fundamentales de la Unión Europea (en adelante, "CDFUE») así como en el artículo 16 del Tratado de Funcionamiento de la Unión Europea (en adelante, «TFUE») y en el artículo 39 del Tratado de la Unión Europea («TUE» en lo sucesivo), artículos éstos dos últimos que ordenan la adopción de normas en esta materia, tanto en el ámbito de aplicación del derecho de la Unión como en el de la política exterior y de seguridad común respectivamente.

En cumplimiento de las directrices fijadas por el art. 16 TFUE se adoptó el Reglamento (UE) 2016/679 del Parlamento Europeo y del

${ }^{3}$ REBOLLO DELGADO, L: «Veinticinco años de relación entre la informática y los derechos al honor y a la intimidad personal y familiar». Revista de Derecho Político, N. ${ }^{\circ}$ 58-59 (2003-2004). Págs. 222-223.

${ }^{4}$ SCHAFER, B:» Compelling truth: legal protection of the infosphere against big data spills». Philosophical Transactions Royal Society A 374:20160114. Pág. 1. Versión electrónica en: http://dx.doi.org/10.1098/rsta.2016.0114.

5 Aunque una manipulación indebida de cierto tipo de datos también puede causar otro tipo de daños y perjuicios, como económicos y financieros.

${ }^{6}$ RUIZ MIGUEL, C: «El derecho a la protección de los datos personales en la Carta de Derechos Fundamentales de la Unión Europea: Análisis crítico». Revista de Derecho Comunitario Europeo, Año 7, N. ${ }^{\circ}$ 14. Enero-abril 2003. Págs. 7-43. Este autor analiza en profundidad el derecho comunitario vigente en ese momento, para concluir que, en relación con el mandato de la cumbre de Colonia de 1999 (de redactar una Carta para consolidar los derechos fundamentales aplicables en la Comunidad). "la Carta de Derechos Fundamentales ha consagrado el derecho a la protección de datos con una redacción desafortunada que... cercena el principio de información e ignora el de confidencialidad y seguridad» (Pág. 41). 
Consejo de 27 de abril de 2016 relativo a la protección de las personas físicas en lo que respecta al tratamiento de datos personales y a la libre circulación de estos datos (Reglamento General de Protección de Datos $)^{7}$, que es la norma general de derecho derivado que desarrolla este derecho fundamental en el territorio de la Unión Europea y, en tanto que Reglamento, es de aplicación obligatoria y directa en todos los Estados miembros, con primacía frente al derecho interno ${ }^{8}$.

La razón fundamental por la que el derecho a la protección de los datos personales en la Unión se ha regulado a través un Reglamento es la voluntad de homogeneizar en todo su territorio el nivel de protección de este derecho fundamental, su armonización con la libertad de circulación de los datos ${ }^{9}$ y su ponderación frente a otros derechos fundamentales ${ }^{10}$, entre otros objetivos. En otras palabras, se eliminan las disparidades entre un Estado miembro y otro en cuanto a la protección y delimitación de los distintos derechos y libertades en juego ${ }^{11}$.

Como podemos observar, el ordenamiento jurídico de la Unión Europea no sólo regula la faceta de derecho fundamental de los datos personales sino que desarrolla otro aspecto que resulta de enorme importancia para la economía actual: La libertad de circu-

${ }^{7}$ Reglamento (UE) 2016/679 DEL PARLAMENTO EUROPEO Y DEL CONSEJO de 27 de abril de 2016 relativo a la protección de las personas físicas en lo que respecta al tratamiento de datos personales y a la libre circulación de estos datos y por el que se deroga la Directiva 95/46/CE (Reglamento General de Protección de Datos), en lo sucesivo RGPD.

8 Art. 288 del TFUE. Con respecto a la primacía de las normas europeas sobre las disposiciones constitucionales en España, consultar PUNSET BLANCO, R: «Derechos fundamentales y primacía del derecho europeo antes y después del caso Melloni». Teoría y Realidad Constitucional, N. ${ }^{\circ} 39,2017$. Págs. 198-200

${ }^{9}$ Cfr. PIÑAS MAÑAS, J.L: «IV. Objeto del reglamento». En Piñar Mañas, J.L. (Dir): Reglamento General de Protección de Datos. Hacia un nuevo modelo europeo de privacidad. Ed. Reus, Madrid, 2016. Págs. 51-62.

${ }_{10}$ Considerando 10 del RGPD. Aunque GARCÍA MEXÍA sostiene que la diferencia que se ha logrado con respecto al uso de una directiva no es significativa: GARCÍA MEXIA, P: «La singular naturaleza jurídica del Reglamento General de Protección de datos de la UE. Sus efectos en el acervo nacional sobre protección de datos». En PIÑAR MAÑAS, J.L. (Dir.): Reglamento General de Protección de Datos... cit. Págs. 23-34.

${ }^{11}$ Los inconvenientes que trae aparejada la desigualdad en las legislaciones nacionales sobre protección de datos personales, que es consecuencia de la adopción de una Directiva, están expuestas en TRONCOSO REIGADA, A: «Las redes sociales a la luz de la propuesta de reglamento general de protección de datos personales. Parte una». En "Retos y oportunidades del entretenimiento en Línea» [monográfico en línea]. IDP. Revista de Internet, Derecho y Política. Número 15, págs. 61-75. Pág. 63. 
lación de los datos, tanto personales como no personales, que constituye hoy en día un factor generador de riqueza comparable a las otras cuatro libertades en las que se basa la Unión Europea ${ }^{12}$ : La circulación de personas, mercancías, servicios y capitales. Por lo tanto, el RGPD se erige también en el instrumento de protección de la libertad de circulación de este tipo de datos dentro del territorio de la Unión Europea por ser primordial para la economía de la Unión y de sus Estados miembros que los parámetros establecidos para su protección no impidan su circulación.

Como hemos dejado entrever en los párrafos precedentes, el tratamiento de algunos datos personales puede afectar al ejercicio de otros derechos fundamentales por parte de terceras personas, como la libertad de información ${ }^{13}$ para los tratamientos periodísticos, el derecho a la educación cuando no se puede transmitir la enseñanza sin el tratamiento de datos relacionadas con las mismas, la libre expresión de ideas ${ }^{14}$, la libertad de prensa, el ejercicio de las artes y las ciencias (especialmente ciencias sociales tales como la historia y la estadística) cuando el estudio y la expresión de ideas sobre los fenómenos sociales no se podría realizar sin el tratamiento de algunos datos de personas relacionadas con dichos fenómenos.

Por esos motivos, en cuanto el derecho que estamos analizando colisiona con otros bienes jurídicos tales como la libertad de circulación de los datos, el derecho a la información o la libertad de expresión (entre otros), se hace necesario proceder a una ponderación de cada uno de ellos, tanto al nivel general de la legislación como a nivel de la casuística de la práctica administrativa o de la jurisprudencia, para decidir hasta dónde se extiende o debe ceder la protección de unos frente a otros, ya que en abstracto ninguno de estos derechos es absoluto ni tiene prioridad frente a los demás. En muchas ocasiones las normas generales pueden determinar la prioridad de unos frente a otros, pero en otras será necesario hacer un estudio ex-

12 Tal es la importancia de los datos en la economía actual que éstos son denominados «el nuevo petróleo». Vid HIRSCH, D: «The Glass House Effect: Big data, the new oil, and the power of analogy. Maine Law Review, Volumen 66 N. $^{\circ} 2$ (2014).

${ }_{13}$ Para un análisis de las colisiones entre el derecho a la intimidad y el derecho a la información, cfr. LORENTE LÓPEZ, M.C: «Los derechos al honor, a la intimidad personal y familiar y a la propia imagen en la jurisprudencia más reciente». En Los derechos a la intimidad y a la privacidad en el Siglo XXI. Ed. Dykinson, Madrid, 2015, págs. 131-155.

${ }_{14}$ MUÑOZ-MACHADO CAÑAS, J: «Tratamiento de datos y libertad de expresión e información». En PIÑAR MAÑAS, J.L. (Dir.): Reglamento General de Protección de Datos... cit. Págs. 587-599. 
haustivo del caso para determinar el límite de cada uno de estos derechos o intereses.

Por su parte, en la constitución española el derecho a la protección de los datos personales no está reconocido de forma autónoma. El artículo 18.4 dispone que «la ley limitará el uso de la informática para garantizar el honor y la intimidad personal de los ciudadanos y el pleno ejercicio de sus derechos», haciendo así una reserva legal para poner límites al uso de la informática, «... para evitar la colisión directa entre el derecho a la intimidad con las necesidades informáticas, fundamentalmente de los poderes públicos» ${ }^{15}$.

A nivel legislativo, el 6 de diciembre de 2018 se publicó en el Boletín Oficial del Estado la Ley Orgánica 3/2018, de 5 de diciembre, de Protección de Datos personales y garantía de los derechos digitales ${ }^{16}$, que entró en vigor al día siguiente de su publicación, es decir el 7 de diciembre. Esta Ley Orgánica tiene como objetivo adaptar el derecho interno español al RGPD.

\section{LA PROTECCIÓN DE DATOS PERSONALES EN EL REGLAMENTO GENERAL DE LA UNIÓN EUROPEA}

\section{A. Garantías y sanciones}

Una de las características de la protección de los datos personales en tanto que derecho fundamental es que los tratamientos de este tipo de información son realizados en igual medida por entes y autoridades públicas como por personas privadas, a diferencia de otros derechos fundamentales que son amenazados, en forma exclusiva o preponderante, por organismos o entidades de derecho público ${ }^{17}$ por

15 REBOLlO DELGADO, L: «Veinticinco años...» cit., Pág. 220.

16 En adelante, «LO 3/2018».

$17 \mathrm{Al}$ respecto, en el ámbito de la Unión Europea, la protección de los derechos fundamentales otorgada por la CFUE está dirigida sólo a personas de derecho público, como surge de su art. 51.1 que establece que sus disposiciones «... están dirigidas a las instituciones, órganos y organismos de la Unión... así como a los Estados miembros únicamente cuando apliquen el Derecho de la Unión...». Por ello, para algunos derechos fundamentales (como es el caso del derecho a la intimidad -art. 7 CDFUE - y la protección de datos personales — art. 8 CDFUE-) existen normas de derecho derivado (la derogada Directiva 46/95; el RGPD; la Directiva 2002/58) que los desarrollan y adecuan su aplicación a los particulares. Sin perjuicio de ello, el TJUE se pronuncia claramente en el sentido de que algunos tratamientos de datos personales (en el caso concreto, su conservación) realizados por particulares pueden afectar de forma directa al derecho a la vida privada establecido en el art. 7 de la CDFUE y a la protección de datos personales del art. 8 CDFUE, en la Sentencia Digital Rights Ireland, apartados 25, 28, 29, 55 y, especial- 
lo que gran parte de sus garantías están configurados para desplegar su eficacia en el ámbito de la actividad de los órganos y autoridades del estado. Por otra parte en el ámbito de la protección de datos, como el mismo título del RGPD lo deja claro, el sujeto protegido es siempre la persona física ${ }^{18}$.

Para entender mejor algunos aspectos analizados en este artículo citaremos a continuación las definiciones sobre las personas intervinientes en las relaciones de tratamientos de datos personales que el RGPD contiene en su artículo 4 y que consideramos fundamentales con el objetivo previamente descrito:

1. Apartado 1): «Interesado»: "Toda persona física... cuya identidad pueda determinarse, directa o indirectamente, en particular mediante un identificador... o uno o varios elementos propios de la identidad física, fisiológica, genética, psíquica, económica, cultural o social de dicha persona».

2. Apartado 2): «Tratamiento»(de datos personales): «Cualquier operación o conjunto de operaciones realizadas sobre datos personales...»

3. Apartado 7): «Responsable del tratamiento»: "La persona física o jurídica, autoridad pública, servicio u otro organismo que, solo o junto con otros, determine los fines y medios el tratamiento...»

4. Apartado 8) «Encargado del tratamiento»: «la persona física o jurídica, autoridad pública, servicio u otro organismo que trate datos personales por cuenta del responsable del tratamiento».

mente, en los apartados 30 y 34, en que reconoce que la cuestión prejudicial planteada se refiere a la adecuación de un tratamiento de conservación de datos personales al art. 8 de la CFUE e, indirectamente, a la validez de las disposiciones de la Directiva 2006/24 que imponen dicha conservación.

En otros pronunciamientos el TJUE ha invocado los referidos artículos de la Carta como pauta interpretativa de la Directiva incluso para las relaciones entre particulares, entre otras, en la Sentencia Schrems (apartados 38, 39). Cfr. UGARTEMENDIA ECEIZABARRENA, J.I: «La eficacia entre particulares de la Carta de Derechos Fundamentales de la Unión Europea a la luz de la jurisprudencia del Tribunal de Justicia» Teoría y Realidad Constitucional, N. ${ }^{\circ}$ 39, págs. 361-386.

18 La protección de datos personales como derecho autónomo es un derecho fundamental que protege exclusivamente al ser humano; sin perjuicio de ello, algunos tratamientos de los datos de personas jurídicas pueden vulnerar otros derechos fundamentales que sí son reconocidos a estos entes, como el derecho al honor. Cfr. STC 139/1995, de 26 de septiembre; GÓMEZ GARRIDO, J: «Derecho al honor y persona jurídica-privada». REDUR 8, diciembre 2010, págs. 205-225. 
En definitiva, las personas o agentes intervinientes en las relaciones de tratamientos de datos personales son: El responsable del tratamiento, que es la persona o entidad, pública o privada, que determina los fines y medios del tratamiento de datos personales; el encargado es la persona o entidad, pública o privada, a quien el responsable haya designado para tratar los datos personales bajo su autoridad, y el interesado es la persona a quien los datos personales identifican.

El diseño de la protección de los datos personales que instaura el RGPD descansa en gran medida en la noción de riesgo para los derechos y libertades de los interesados ${ }^{19}$ y se basa principalmente en una serie de medidas de garantía, consistentes en:

1. Principios que los tratamientos deben respetar (arts. 5 a 10),

2. Derechos de los interesados (Capítulo III, arts. 12 a 23$)^{20}$ y

3. Obligaciones a cargo del responsable y del encargado, que se corresponden tanto con los principios de los tratamientos como con los derechos de los interesados, por lo que se pueden inferir de los artículos precedentemente citados y también de los artículos 24 a 36 RGPD.

4. Establecimiento de autoridades de control y supervisión de la aplicación del Reglamento en todos los Estados miembros.

Nos detendremos en este análisis en algunos de los deberes que se imponen a los responsables de los tratamientos (Punto 3), entre los cuales se encuentran: aplicar políticas de protección de datos que sean proporcionadas con las actividades de tratamiento (art. 24.2 RGPD), suministrar determinada información a los interesados (arts. 12 a 14 RGPD), minimizar la cantidad de datos recogidos, el tiempo de conservación y el número de personas con acceso a ellos (arts. 5.c y 25 RGPD) y garantizar la seguridad de los datos que son sometidos a tratamiento bajo su responsabilidad (arts. 5.f y 32 RGPD), protegiéndolos contra el acceso no autorizado o ilícito así como contra su pérdida, destrucción o daño

19 Por ejemplo, art. 24.1; art. 25.1; art. 27.2.a); art. 32.1 del RGPD. Vid al respecto: RECIO GAYO, M: «XXI. Aproximación basada en el riesgo, evaluación de impacto relativa a la protección de datos personales y consulta previa a la autoridad de control». En PIÑAR MAÑAS, J.L: Reglamento General de Protección de Datos... cit., págs. 351-366.

${ }_{20}$ Para profundizar los principios y derechos establecidos en el RGPD, consultar REBOLLO DELGADO, L: Protección de datos en Europa... (cit.), págs. 101 a 129. 
EL DEBER DE NOTIFICAR Y EL DERECHO A LA NO AUTOINCULPACIÓN...

accidental; responsabilidad ésta que comparte con los encargados de los tratamientos ${ }^{21}$.

El art. 24 RGPD, por su parte, establece la obligación para los responsables de los tratamientos, de «garantizar y poder demostrar que el tratamiento es conforme» con el Reglamento, obligación que se corresponde con el principio de responsabilidad proactiva del artículo 5.2 RGPD, y que no se concreta en un determinado hacer o no hacer específico, sino que se exige como un modo de actuar transversal a todo el Reglamento y se debe respetar en cada una de las actividades y responsabilidades relacionadas con los tratamientos de datos personales.

El art. 32 RGPD impone a los responsables y encargados del tratamiento la obligación de aplicar «... medidas técnicas y organizativas apropiadas para garantizar un nivel de seguridad adecuado al riesgo...». La calidad de apropiadas de las medidas se determinará en base a los «... riesgos de probabilidad y gravedad variables para los derechos y libertades de las personas físicas... » entre otros criterios. Advertimos aquí que seguridad de los datos no es lo mismo que seguridad informática, ya que existen métodos de protección de los datos, como por ejemplo la anonimización o seudonimización, el cifrado o codificación de la información, que permiten mantener su seguridad incluso ante una violación de la seguridad de los sistemas informáticos o de almacenamiento.

Por otra parte, los riesgos que pueden resultar para los derechos y libertades de las personas por las violaciones de la seguridad de los datos son muy variados y dependen en gran medida de la naturaleza de los datos que se están tratando. Se agravan, por ejemplo, con la manipulación ilícita y, especialmente, difusión o publicación indebida de datos pertenecientes a las categorías especialmente protegidas que se enumeran en el artículo 9 RGPD (datos étnicos o raciales, opiniones filosóficas, religiosas o políticas, datos genéticos y biométricos, datos sobre la salud ${ }^{22}$ o la orientación sexual, etc.) y algunas otras categorías que, aunque no están especialmente protegidos, si son sometidos a operaciones indeseadas pueden generar serios perjuicios tanto morales (como los datos o imágenes relacionados con

${ }^{21}$ Otras obligaciones y derechos son analizados por ORTEGA GIMÉNEZ, A. y GONZALO DOMENECH, J.J: "Nuevo marco jurídico en materia de protección de datos de carácter personal en la Unión Europea». Revista de la Facultad de Derecho de la Universidad de la República (Montevideo), N. ${ }^{\circ}$ 44, ene-jun 2018. Págs. 63-97.

${ }^{22}$ Respecto a los tratamientos de datos de la salud, cfr. ÁLVAREZ RIGAUDIAS, C: «XI. Tratamiento de datos de salud». En PIÑAR MAÑAS, J.L: Reglamento General de Protección de Datos... cit. Págs. 171-185.

(c) UNED. Revista de Derecho UNED, núm. 24, 2019 
la vida íntima o afectiva) o materiales (datos financieros o bancarios).

Dada la importancia de los valores en juego, el art. 83 RGPD establece dos niveles de multas por incumplimiento de las obligaciones a cargo de responsables y encargados de los tratamientos (y también de otros agentes), que por su onerosidad tienen el objetivo de compeler a estos actores a cumplir sus obligaciones y de incitarlos a no subestimar los perjuicios que su negligencia o simple indolencia puede causar a los interesados. En otras palabras, una de las finalidades de las sanciones es coaccionar a los responsables y encargados para que cumplan sus obligaciones.

Los dos niveles de sanciones establecidos en el mencionado artículo, para los cuales se determinan los importes máximos pero no los mínimos, son los siguientes:

a) El nivel más bajo, cuya cuantía máxima se establece en $10.000 .000 €$ o el $2 \%$ de la facturación a nivel global del ejercicio anterior si el infractor es una empresa. Esta sanción se establece para las infracciones que consistan, en general, en el incumplimiento de las distintas obligaciones instauradas a cargo de los responsables o encargados de los tratamientos (art. 83.4.a RGPD) y de los organismos de certificación (Art. 83.4.b RGPD) ${ }^{23}$;

b) El otro nivel puede ascender a los $20.000 .000 €$ o el $4 \%$ de la facturación a nivel global del ejercicio anterior para las empresas, que se puede imponer para las infracciones contra los principios de los tratamientos, los derechos de los interesados, las condiciones que deben cumplir las transferencias internacionales de datos personales, las condiciones establecidas para los tratamientos específicos de datos personales establecidos en el Capítulo IX del RGPD ${ }^{24}$ o la desobediencia a una o más

${ }^{23} \mathrm{El}$ art. 83.4.c) RGPD dispone que esta misma cuantía se puede imponer a las autoridades de protección de datos por el incumplimiento de las obligaciones a su cargo, pero en este artículo obviamos ese tema por ser más complejo, al menos en la cuestión atinente a las infracciones al RGPD cometidas por la autoridad nacional de protección de datos, que obviamente no podrá ser impuesta por ésta sino que deberá serlo por el poder judicial. Por el contrario, la autoridad nacional sí podría imponer sanciones administrativas a las autoridades locales o de entidades territoriales descentralizadas, lo que dependerá de la organización política de cada Estado miembro.

${ }^{24}$ Este capítulo regula los tratamientos relacionados con la libertad de expresión y de información (art. 85), con el acceso del público a documentos oficiales (art. 86), con el número de identificación nacional (art. 87), con el ámbito laboral 
resoluciones de la autoridad de protección de datos (Art. 83.5, subapartados a, b, c, d y e RGPD) ${ }^{25}$.

La facultad de imponer las sanciones administrativas precedentemente descritas y adecuar el importe de las mismas a cada caso concreto se atribuye a las autoridades de protección de datos ${ }^{26}$ (art. 83, apartados 1 y 2 RGPD).

Por otra parte, en el art. 58 apartado 2) del RGPD se inviste a las APD de otros "poderes correctivos", algunos de los cuales tienen verdadera naturaleza sancionadora ${ }^{27}$, tales como la advertencia y el apercibimiento (subapartados a) y b) respectivamente), la limitación o prohibición del tratamiento (subapartado f) o la suspensión de las comunicaciones de datos personales a destinatarios en un país tercero (subapartado j).

\section{B. La obligación de notificación de las brechas de seguridad}

El art. 33.1 del RGPD introduce para el responsable del tratamiento una obligación que no existía en la normativa anterior ${ }^{28}$ : la de notificar a la autoridad de protección de datos las violaciones de la seguridad de los datos personales que estén sometidos a un tratamiento, cuando sea probable que entrañen un riesgo para los derechos y libertades de las personas físicas. Si el riesgo es alto, la notificación se debe realizar también al interesado (art. 34.1 RGPD). El art. 33.2 impone también al encargado la obligación de notificar las brechas de seguridad, pero sólo a la APD.

Entendemos, como la Agencia Española de Protección de Datos (en adelante, "AEPD»), "por brecha de seguridad o violación de la seguridad de los datos personales todo aquel incidente de seguridad que provoque la destrucción, pérdida o alteración accidental o ilícita de da-

(art. 88), con distintas finalidades como el archivo en interés público, la investigación o la estadística (art. 89), con la obligación de secreto (art. 90) o con las iglesias y asociaciones religiosas (art. 91).

${ }^{25}$ Estas disposiciones están complementadas por el Título IX de la LO 3/2018

${ }^{26}$ En adelante, «APD».

${ }^{27}$ Cfr. CORRAL SASTRE, A: «XXXI. El régimen sancionador en materia de protección de datos en el Reglamento General de la Unión Europea». En PIÑAR MAÑAS, J.L. (Dir.): Reglamento General de Protección de Datos... cit. Págs. 571-585.

${ }_{28}$ MAYOR GÓMEZ, R: «Contenido y novedades del Reglamento General de Protección de Datos de la UE (Reglamento UE 2016/679, de 27 de abril de 2016». Gabilex, N. ${ }^{\circ}$ 6, junio 2016. Pág. 269. 
tos personales transmitidos, conservados o tratados de otra forma, o la comunicación o acceso no autorizado a dichos datos» ${ }^{29}$.

El responsable del tratamiento debe notificar a la APD la violación de seguridad, "sin dilación indebida y, de ser posible, a más tardar 72 horas después de que haya tenido constancia de ella... $»^{30}$ En caso de imposibilidad de notificar la violación antes de las 72 horas (lo que se deberá justificar y acreditar, en base al principio de responsabilidad proactiva), la información se podrá entregar en forma gradual a efectos de no dilatar indebidamente su comunicación ${ }^{31}$.

El apartado 3 del art. 33 dispone que la información a suministrar a la APD incluirá como mínimo:

1. La naturaleza de la violación y, cuando sea posible, las categorías de datos, el número (aunque sea aproximado) de interesados afectados y los detalles de los registros afectados;

2. Las posibles consecuencias (interpretamos que se refiere a los riesgos para los derechos y libertades) de la violación de seguridad;

3. Las medidas adoptadas o que el responsable propone adoptar para contrarrestar los efectos de la violación de seguridad;

4. Los datos del delegado o de otra persona de contacto para gestionar el asunto.

La notificación que el responsable tiene obligación de enviar a la APD consiste sin lugar a dudas en una declaración ${ }^{32}$ que puede tener como objeto hechos ajenos o propios y, siendo una de las obligaciones a su cargo en el RGPD, su incumplimiento está penalizado con una multa que en este caso correspondería al nivel más bajo de los indicados en el apartado anterior de este Capítulo.

El Considerando 86, al igual que el art. 34 del RGPD, se refieren a la obligación de notificar al interesado las violaciones que puedan

${ }^{29}$ Definición obtenida del sector la página web de la AEPD dedicado a las notificaciones de las brechas o violaciones de seguridad: https://sedeagpd.gob.es/sedeelectronica-web/vistas/formBrechaSeguridad/ procedimientoBrechaSeguridad.jsf (último acceso 08/10/2018).

30 Art. 33.1 RGPD.

31 Considerando 85 y art. 33.4 del RGPD.

${ }^{32}$ Cfr. SANZ DÍAZ-PALACIOS, J.A: Derecho a no autoinculparse y delitos contra la Hacienda Pública, Colex, Madrid, 2004, págs. . 61-64. A esta concepción de lo que constituye una declaración volveremos más adelante, en Capitulo II Apartado B.3 de esta investigación. 
EL DEBER DE NOTIFICAR Y EL DERECHO A LA NO AUTOINCULPACIÓN...

entrañar un alto riesgo para sus derechos y libertades ${ }^{33}$, entre otros fines para permitirle adoptar las precauciones necesarias, debiendo acompañarse a la notificación una recomendación sobre tales medidas, una de las cuales será, según el caso, el cambio de contraseñas de acceso.

La APD, en virtud de su objetivo de vigilar la aplicación del RGPD, deberá evaluar la situación causada por la violación de seguridad y adoptar las medidas que deriven de sus facultades y poderes (especialmente, los de investigación), según lo aconsejan los considerandos 87 y 88, que llegan incluso a indicar que la notificación "puede resultar en una intervención de la autoridad de control de conformidad con las funciones y poderes que establece el presente Reglamento ${ }^{34}$.

El Considerando 88 abre la puerta para que se evalúen las medidas adoptadas por el responsable con respecto a la seguridad de los datos y aconseja tener en cuenta las necesidades de las autoridades policiales si existe una investigación en curso sobre dicha violación.

Para finalizar con la regulación del deber de notificar en el Reglamento, el apartado 5 del art. 33 RGPD ordena al responsable documentar con detalle las violaciones de seguridad, sus efectos y las medidas correctivas adoptadas, con el objetivo de permitir a la APD verificar el cumplimiento de sus obligaciones al respecto. Obsérvese aquí que el artículo no impone la obligación de notificar o entregar a la APD dicha documentación, de lo que se infiere que ésta la podrá recabar de acuerdo con los sus poderes y facultades de investigación.

Como se puede observar, la información que el responsable tiene obligación de entregar a la APD tiene como efecto la apertura de una investigación por parte de ésta y puede motivar el ejercicio de otros poderes y facultades que le confieren los distintos artículos del RGPD, entre ellos la facultad de investigar si el responsable y el encargado han cumplido todas las obligaciones a su cargo, y la de imponer sanciones en caso de que descubra que existe algún incumplimiento.

Como es fácil de imaginar, las violaciones de seguridad pueden tener muchas y diversas causas, tales como un acto ilícito (un hackeo informático), un error o negligencia humanos, un fa-

${ }^{33} \mathrm{El}$ art. 58.2.e) faculta a la autoridad de control para ordenar al responsable del tratamiento que notifique una violación al interesado.

${ }^{34}$ Considerando 87 in fine del RGPD. 
llo tecnológico, etc. Pero, en cualquier caso, podrán asimismo ser consecuencia de, o estar relacionadas con, la inobservancia de alguna de las obligaciones a cargo de responsable o encargado, teniendo especialmente en cuenta la gran cantidad y complejidad de éstas y, asimismo, que ambos agentes tendrán responsabilidad objetiva por la actuación de sus dependientes. En estos casos, la notificación que tienen obligación de realizar puede implicar el reconocimiento de un incumplimiento por parte del responsable o encargado que notifique.

En síntesis, ante una violación de la seguridad de los datos el responsable tendrá la obligación de informar sobre ese hecho pues la falta de información constituirá una infracción susceptible de ser sancionada con las multas administrativas del nivel más bajo del art. 83.4 RGPD. A su vez, la notificación de la brecha puede dar inicio a una investigación por parte de la APD, que puede resultar en el descubrimiento de un incumplimiento que conduzca igualmente a una sanción administrativa.

En los casos en que la brecha de seguridad esté relacionada con un delito, por ejemplo de descubrimiento y revelación de secretos ${ }^{35}$ o de violación de la seguridad informática ${ }^{36}$, el hecho se debe poner en conocimiento de la autoridad pública correspondiente, conforme a lo establecido por el art. 259 de la Ley de Enjuiciamiento Criminal, denuncia que desplegará los efectos pertinentes según la regulación de la materia. Pero esta notificación no libera al responsable y al encargado de la obligación de comunicar la violación de la seguridad también a la APD, autoridad que está investida con poderes y facultades suficientes para iniciar una investigación administrativa, tramitar expedientes sancionadores e imponer multas administrativas tal como veremos a continuación.

\section{Autoridades de protección de datos: Facultades y poderes}

Como hemos adelantado en la Introducción de este artículo, la protección frente al tratamiento ilegítimo de los datos personales es un derecho fundamental autónomo que se configura asimismo como protección para la defensa de otros derechos fundamentales $\mathrm{y}$, a su vez, en muchas ocasiones debe ser armonizado con otros derechos y libertades de terceras personas y con la libertad de circulación de los datos.

35 Art. 197 Código Penal.

${ }^{36}$ Arts. 197 bis, ter, quater y quinquies del Cód. Penal 
A efectos de garantizar y armonizar tales derechos así como la efectividad de las medidas establecidas para su protección, existen en los Estados miembros autoridades específicas para la protección de los datos personales que encuentran en el RGPD ${ }^{37}$ las líneas básicas de su organización, facultades y funciones ${ }^{38}$, también a efectos de homogeneizarlas en todo el territorio de la Unión ${ }^{39}$. En los artículos 57 y 58, el RGPD fija las funciones y poderes de que deben estar investidas las APD, que se establecen como mínimos, es decir que el Estado miembro de designación puede complementarlas y ampliarlas, pero nunca reducirlas.

Entre las numerosas prerrogativas y tanto en calidad de función (art. 57.1.h RGPD) como en calidad de poder (art. 58.1 RGPD) se incluye la posibilidad de realizar investigaciones, que pueden tener la forma de auditorías (art. 58.1.b RGPD), complementadas por diversos otros poderes tales como el de ordenar al responsable y al encargado del tratamiento que les entregue (art. 58.1.a RGPD), o que les dé acceso a toda la información que necesiten así como a todos los datos personales que estén siendo sometidos a tratamiento (art. 58.1.e RGPD) y también a los locales, equipos y medios de tratamiento (art. 58.1.f RGPD).

En el plano nacional, la LO 3/2018 complementa las disposiciones sobre las facultades y poderes de investigación de la AEPD, que la misma ley prevé que se rige en primer lugar por el RGPD (arts. 45.1 y 47) y, en segundo término, por sus Títulos VII y VIII y el resto de los artículos que le resulten aplicables. Entre las facultades que esta ley establece como adicionales a las otorgadas por el RGPD figuran la posibilidad de recabar datos e información de las admi-

37 Capítulo VI del RGPD, arts. 51 a 59.

38 Para profundizar en las características de la regulación sobre las APD, vid REBOLLO DELGADO, L: Protección de datos en Europa... (cit.) págs. 196-199 y TRONCOSO REIGADA, A: «XXVI. Autoridades de control independientes». En PIÑAR MAÑAS, J.L: Reglamento General de Protección de Datos... cit. Págs. 461-512.

${ }^{39}$ La autoridad central de protección de datos en España es la Agencia Española de Protección de Datos (en adelante, «AEPD»), dirección electrónica: www. aepd.es, existiendo también autoridades autonómicas en Cataluña: Autoritat Catalana de Protecció de Dades o Autoridad Catalana de Protección de Datos, dirección electrónica: http://apdcat.gencat.cat/ca/inici y en el País Vasco: Datuak Babesteko Euskal Bulegoa o Agencia Vasca de Protección de Datos, dirección electrónica: http://www.avpd.euskadi.eus/s04-5213/es/ (último acceso a todas las páginas web indicadas el 08/10/2018). La Comunidad de Madrid contó con una Agencia de Protección de Datos, creada por la Ley 8/2001, de 13 de julio, de Protección de Datos de Carácter Personal en la Comunidad de Madrid y extinguida por el art. 61 de la Ley 8/2012, de 28 de diciembre, de Medidas Fiscales y Administrativas de la Comunidad de Madrid. 
nistraciones públicas ${ }^{40}$ así como de los operadores de servicios de comunicaciones electrónicas accesibles para el público y de los prestadores de servicios de la sociedad de la información ${ }^{41}$. Podrá asimismo trazar planes de auditoría preventiva a un sector concreto de $\operatorname{actividad}^{42}$.

Volviendo al RGPD, las APD tienen, además de los poderes de investigación, entre otros, los poderes correctivos o sancionadores que ya hemos mencionado ${ }^{43}$. Dado que la notificación de las brechas de seguridad es una obligación más a cargo de los responsables de los tratamientos, ante su incumplimiento (es decir, ante la omisión de notificación de una violación de la seguridad de los datos) las APD pueden ejercer todos estos poderes, imponiendo cualquiera de las correcciones o sanciones al responsable incumplidor.

Finalmente, sin perjuicio de la calidad de autoridad independiente que le otorga los arts. 51 y 52 del RGPD y los concordantes de la LO 3/2018, la AEPD forma parte de la administración pública española y está, por consiguiente, en todo lo que no se contradiga con las normas específicas ya citadas, sometida a la Ley 39/2015, de 1 de octubre, del Procedimiento Administrativo Común de las Administraciones Públicas (en lo sucesivo, «Ley 39/15») y a la Ley 40/2015, de 1 de octubre, de Régimen Jurídico del Sector Público (en adelante, «Ley 40/15»).

\section{COLISIÓN CON EL DERECHO A LA NO AUTOINCULPACIÓN}

\section{A. Planteamiento del problema}

Tal como hemos visto en el apartado B. del capítulo anterior, la notificación de las brechas de seguridad a la APD es una obligación a cargo de responsables y encargados del tratamiento, cuya ejecución está sometido a coacción dado que su incumplimiento puede ser sancionado con multas administrativas del artículo 83.4.a) RGPD. Ahora bien, los mencionados agentes también pueden ser sancionados si la notificación o la investigación que se derive de la

40 Arts. 52.1) y 52.2) LO 3/2018.

${ }^{41}$ Art. 52.3) LO 3/2018, en el cual se detallan a nuestro entender taxativamente los datos que se pueden obtener, las condiciones y limitaciones de esta potestad.

42 Art. 54 LO 3/2018.

43 Apartado 1) de este Capítulo. 
misma deja al descubierto el incumplimiento de una o más obligaciones a cargo de quien la presenta.

Hemos llegado aquí al objeto principal de nuestra investigación, que se centra en el dilema ante el que se encuentra el responsable o encargado de un tratamiento de datos que si omite la notificación puede ser sancionado, pero también puede serlo si notifica la violación y deja al descubierto un incumplimiento por el que resultará responsable.

Por todo ello, la ejecución de esta obligación bajo coacción puede colisionar con algunos derechos fundamentales del sistema multinivel que se aplica en España ${ }^{44}$, nos referimos a derechos reconocidos en el Convenio Europeo de Derechos Humanos ${ }^{45}$, en la Carta de los Derechos Fundamentales de la Unión Europea ${ }^{46}$ y en la Constitución Española ${ }^{47}$ como exponemos a continuación:

1. CEDH, art. 6: "Derecho a un proceso equitativo»: Apartado 2: "Toda persona acusada de una infracción se presume inocente hasta que su culpabilidad haya sido legalmente declarada».

2. CEDH, Art. 6, apartado 3: «Todo acusado tiene, como mínimo, los siguientes derechos...». En este apartado se enumeran un conjunto de garantías de naturaleza procesal, que no hacen referencia a la prueba en general (sólo al interrogatorio de los testigos) ni a su relación con otros derechos fundamentales, pero que constituyen un contenido de mínimos que en la práctica ha sido ampliada por la jurisprudencia del Tribunal Europeo de Derechos Humanos, tal como veremos más adelante.

3. CDFUE, Art. 20: Igualdad de «todas las personas» ante la ley, derecho que no está adscrito a la condición de ciudadano y que, en una interpretación amplia, se ve vulnerado cuando una de las partes en un procedimiento es coaccionada para presentar una prueba que la perjudica.

4. CDFUE, Título VI: Tiene también un contenido de mínimos dedicado a los derechos y garantías relacionados con la administración de justicia en la Unión y en sus Estados miembros. En los artículos que lo componen instaura el derecho a la tutela judicial efectiva y a un juez imparcial (art. 47), a la presunción de inocencia y al respeto a «los derechos de defensa»

${ }^{44}$ GÓMEZ SÁNCHEZ, Y: Op. Cit, págs. 45-60.

45 En adelante, «CEDH».

46 En adelante, "CDFUE» 0 «La Carta».

47 En adelante, «CE». 
(art. 48) que están garantizados "a todo acusado» y entre los cuales consideramos incluido el derecho a medios de prueba legítimos, es decir que, entre otros requisitos, no se hayan obtenido con vulneración de derechos fundamentales. Los otros principios reconocidos en este Título son los de legalidad y proporcionalidad (art. 49) y el ne bis in eadem (art. 50).

5. CE, Art. 14: Igualdad ante la ley, en su interpretación amplia como igualdad procesal y administrativa, dado que quien se ve obligado a comunicar la comisión de una infracción que puede dar lugar a una sanción no está en igualdad de condiciones que el resto de los administrados, que no se ven compelidos a denunciar su propio incumplimiento.

6. CE, Art. 24.2: Derecho a no confesarse culpable, a utilizar los medios pertinentes para su defensa y a la presunción de inocencia, todo lo cual forma parte del derecho a un proceso público con todas las garantías.

\section{B. Soluciones en la legislación, la jurisprudencia y la doctrina}

\section{En la legislación española}

Para intentar resolver el dilema planteado acudiremos en primer lugar a las disposiciones del ordenamiento jurídico español:

a) El art. 11.1 de la Ley Orgánica del Poder Judicial (en adelante, «LOPJ»), que dispone que «no surtirán efecto las pruebas obtenidas, directa o indirectamente, violentando los derechos o libertades fundamentales». Esta disposición, dirigida a los órganos judiciales, les impediría utilizar como prueba la notificación de una violación de seguridad en la que el responsable o encargado que la realice reconozca un incumplimiento propio.

b) El art. 77.1 de la Ley 39/15, en virtud del cual los hechos relevantes para los procedimientos se podrán acreditar por medios de prueba admisibles en Derecho y de acuerdo con los criterios establecidos en la Ley 1/2000 que exponemos a continuación.

c) La Ley 1/2000, de 7 de enero, de Enjuiciamiento Civil, en los artículos 283.3 y 287, el primero de los cuales proscribe la admisión como prueba de "cualquier actividad prohibida por la ley». El segundo artículo citado dispone que de oficio o a instancia de parte, el juez debe resolver sobre la prueba en cuya obtención u origen se hayan vulnerado derechos fundamentales. 
2. En la jurisprudencia

\section{a) Tribunal Europeo de Derechos Humanos}

Tal como hemos recordado en el apartado A de este Capítulo, el artículo 6 del CEDH en su apartado 2 garantiza la presunción de inocencia. El apartado 3 del mencionado artículo desarrolla la garantía del proceso equitativo, con distintas manifestaciones concretas en sus subapartados, ninguna de las cuales es el derecho a la no autoincriminación, que no está mencionado en este artículo ${ }^{48}$.

No obstante, el Tribunal Europeo de Derechos Humanos ${ }^{49}$ ha declarado en jurisprudencia constante que, aunque este artículo no los mencione expresamente, el derecho a negarse a declarar y el derecho a la no autoincriminación, ambos íntimamente ligados entre sí, son principios internacionalmente reconocidos que persiguen la protección del acusado contra una coerción abusiva por parte de las autoridades y que están implícitos en la noción de proceso equitativo consagrado en el artículo 6 del $\mathrm{CEDH}^{50}$. Más precisamente, ambos derechos forman parte de la noción de equidad que emana del citado artículo ${ }^{51}$.

El TEDH concibe el derecho a negarse a declarar, ante todo, como respeto a la voluntad del acusado de guardar silencio, lo que obliga a la acusación en un caso penal a basarse en pruebas que no se apoyen en evidencia obtenida a través de métodos coercitivos y en contra de la voluntad del acusado ${ }^{52}$.

${ }^{48} \mathrm{El}$ apartado 3 del art. 6 CEDH establece textualmente:

«3. Todo acusado tiene, como mínimo, los siguientes derechos:

a) a ser informado, en el más breve plazo, en una lengua que comprenda y de manera detallada, de la naturaleza y de la causa de la acusación formulada contra él;

b) a disponer del tiempo y de las facilidades necesarias para la preparación de su defensa;

c) a defenderse por sí mismo o a ser asistido por un defensor de su elección y, si carece de medios para pagarlo, a poder ser asistido gratuitamente por un abogado de oficio, cuando los intereses de la justicia así lo exijan;

d) a interrogar o hacer interrogar a los testigos que declaren en su contra y a obtener la citación e interrogatorio de los testigos que declaren en su favor en las mismas condiciones que los testigos que lo hagan en su contra;

e) a ser asistido gratuitamente de un intérprete si no comprende o no habla la lengua empleada en la audiencia.»

${ }_{49}$ En adelante, TEDH

${ }^{50}$ Entre otros, Caso Heaney y McGuiness c/Irlanda , apartado 40; Caso Ibrahim y ots. c/Reino Unido, apartado 266 y la jurisprudencia citada en ellos

51 Caso Saunders, apartado 74.

52 Casos Saunders, apartados 68-69; Jalloh C/Alemania, sentencia de 11 de julio de 2006, apartados 100 y 102; Bykov C/Rusia, sentencia de 10/03/2009, apartado 92 y Annual Reports ECHR 1996-VI. 
Igualmente, en vista del concepto de equidad o justicia que emana del art. $6 \mathrm{CEDH}$, la declaración realizada bajo coacción legal (es decir, bajo amenaza de que la negativa a declarar puede significar una pena de multa o de prisión) constituye una vulneración al derecho a la no autoincriminación aunque las afirmaciones en apariencia no sean incriminatorias o sean exculpatorias, ya que pueden ser usadas por la acusación en un procedimiento penal posterior para apoyar sus argumentos ${ }^{53}$. La violación al artículo 6 CEDH en estos casos se produce por la existencia de coacción para declarar, y su utilización como prueba de cargo es ilegítima. Pero por otra parte este derecho no es absoluto, no cualquier coacción es incompatible con el artículo 6 del CEDH sino sólo aquélla que atenta contra el derecho a la no autoincriminación, por lo tanto el Tribunal debe examinar caso por caso la naturaleza y el grado de coacción utilizado para la obtención de la evidencia. Para decidir si ésta es contraria al art. 6 es fundamental determinar el uso que se da a esa evidencia en el curso del procedimiento penal ${ }^{54}$.

Es de destacar que el uso que se da a la evidencia es de particular importancia a la hora de emitir un juicio sobre la legitimidad del procedimiento penal en su conjunto ${ }^{55}$, por lo que se debe analizar este factor, junto a otros tales como: la calidad de la evidencia, las circunstancias en las que fue obtenida, si fue obtenida de manera ilegal, si tal ilegalidad constituye una violación de algún otro artículo del CEDH, si en el caso de una declaración el declarante se retractó o la modificó y por último el interés público implicado en la investigación o en la represión del hecho concreto que se esté investigando ${ }^{56}$. Sin perjuicio de ello, "No se puede invocar el interés público para el uso de respuestas obtenidas bajo compulsión en una investigación no judicial para incriminar al acusado durante el procedimiento judicials ${ }^{57}$. De lo que inferimos que, a pesar de no ser absoluto, el derecho a la no autoinculpación no puede ceder ante cualquier otro bien jurídico sino sólo ante otros de valor superior, aunque como ocurre con la mayoría de los casos de ponderación jurídica de los valores en colisión, no hay norma que establezca la escala de forma predeterminada sino que se debe realizar caso por caso.

53 Caso Brusco C/Francia, sentencia de 14/10/2010, apartado 71.

${ }_{54}$ Entre otros, apartados 267, 268 y 269 del caso Ibrahim y jurisprudencia citada.

${ }^{55}$ Caso Ibrahim, apartado $274 \mathrm{~g}$ ).

${ }^{56}$ Caso Ibrahim, apartados 274 d); e); f) e i).

${ }^{57}$ Caso Saunders, apartado 74. 


\section{b) Tribunal de Justicia de la Unión Europea}

El Tribunal de Justicia de la hoy Unión Europea ha tenido oportunidad de pronunciarse sobre el derecho a la no autoincriminación en casos relacionados con las facultades de investigación de la Comisión en relación con el derecho de la competencia. La primera sentencia sobre este tema es la del caso Orkem C/Comisión ${ }^{58}$, del año 1989. En este caso el demandante invoca el derecho a no declarar y a no autoinculparse como manifestaciones del derecho a la defensa en juicio, contra la actividad de investigación de la Comisión en el marco del Reglamento $\mathrm{n}^{\circ} 17$ del Consejo, de 6 de febrero de 1962, primer Reglamento de aplicación de los artículos 85 y 86 del Tratado CEE (en lo sucesivo, «Reglamento n. ${ }^{\circ} 17$ »).

Esta sentencia es anterior a las sentencias en las que el TEDH reconoce el derecho a la no autoinculpación, por ello en los apartados 28 a 30 el Tribunal manifiesta que este derecho no se encuentra expresamente reconocido en el CEDH ni por el TEDH y que no se puede afirmar que el reconocimiento de este principio en favor de las personas jurídicas en el ámbito de las infracciones administrativas constituya derecho común a los Estados miembros ${ }^{59}$. No obstante, en mérito al derecho de defensa que sí está reconocido en el Reglamento n. ${ }^{\circ} 17$, en los apartados 33 a 35 de la sentencia citada se pronuncia en el sentido de que el mismo debe respetarse en los procedimientos de investigación previa, lo que impide a la Comisión obligar a la empresa a realizar una declaración autoinculpatoria; aunque sí puede obligarla a entregar toda la documentación que obre en su poder sobre los hechos que se investigan ya que la protección otorgada por el derecho de defensa no incluye la entrega de evidencia.

A pesar de que la jurisprudencia del TEDH ha evolucionado hacia la admisión del derecho a la no autoinculpación, el criterio del Tribunal de Justicia no ha variado posteriormente, tal como se evidencia en el apartado 271 de la sentencia «Erste Group Bank $A G »^{60}$.

58 Sentencia del Tribunal de Justicia de 18 de octubre de 1989 , en el asunto $374 / 87$.

${ }^{59}$ Como veremos más adelante, el derecho a la no autoinculpación forma parte de las garantías procesales en la justicia penal, si bien actualmente su aplicación a los procedimientos administrativos sancionadores está fuera de toda duda. El mismo Tribunal reconoce en el apartado 33 de la sentencia Orkem C/Comisión, que «el derecho de defensa debe ser respetado en los procedimientos administrativos que pueden dar lugar a una sanción...».

60 Sentencia del TJUE de 24 de septiembre de 2009 en los autos acumulados C-125/07 P, C-133/07 P, C-135/07 P y C-137/07 P.

(C) UNED. Revista de Derecho UNED, núm. 24, 2019 


\section{c) Tribunal Constitucional}

Independientemente de la vigencia de las normas sobre la admisibilidad de la prueba que hemos expuesto en el apartado A de este capítulo, el Tribunal Constitucional (en lo sucesivo, «TC») ha elaborado una jurisprudencia consolidada respecto al principio que formula como «la prohibición absoluta de valoración de las pruebas obtenidas con vulneración de derechos fundamentales» ${ }^{61}$, basada en la consideración de que, aparte de la violación originaria de éstos (cometida al obtener la prueba), la admisión de esta prueba constituiría una segunda vulneración de los siguientes derechos:

i. La igualdad de las partes en el proceso (art. $14 \mathrm{CE}$ ), ya que causaría una «... desigualdad que se ha procurado antijurídicamente en su provecho quien ha recabado instrumentos probatorios en desprecio a los derechos fundamentales de otro...",

ii. El derecho a un proceso con todas las garantías (art. 24.2 CE) ${ }^{62}$.

Las disposiciones constitucionales que lo fundamentan son el art. 10.1 de la CE, que declara la inviolabilidad de los derechos fundamentales, así como el art. 24 de la CE, en el cual considera implícitamente incluida la prohibición de valorar en juicio las pruebas obtenidas con violación de derechos fundamentales ${ }^{63}$, garantía que no se incluye de forma explícita. Por otra parte, esta garantía se incorpora al sentido técnico-procesal de la necesidad de medios de prueba pertinentes que establece el art. $24.2 \mathrm{CE}^{64}$.

Ahora bien, la validez o invalidez de las pruebas en relación con su obtención por medios lícitos no surge del derecho a la presunción de inocencia (que consiste en el «derecho a no ser condenado sin pruebas de cargo válidas»), sino del derecho a un proceso con todas las garantías. Ello así pues la admisión de pruebas obtenidas con violación de los derechos fundamentales del acusado por sí sola no vulnera la presunción de inocencia; ésta se ve vulnerada si se condena al acusado sólo en base a esas pruebas ilegítimamente adquiridas. En caso de que, aparte de éstas, existan otras pruebas de cargo que sean suficientes para condenar al acusado, se podrá considerar vulnerado el derecho al proceso con to-

${ }^{61}$ Doctrina formulada por primera vez en la STC 114/1984, FJ 4 y 5 y repetida en numerosas sentencias, entre ellas STC 126/2011, FJ 9 y jurisprudencia citada.

${ }^{62}$ Entre otras, STC 50/2000 STC 111/2011, FJ 4 y jurisprudencia citada.

${ }^{63}$ Por todas, STC 126/2011, FJ 9.

64 STC 50/2000, FJ 2. 
EL DEBER DE NOTIFICAR Y EL DERECHO A LA NO AUTOINCULPACIÓN...

das las garantías pero no la presunción de inocencia, dado que ésta se habrá destruido adecuadamente con las pruebas de cargo válidas $^{65}$. En definitiva, podemos afirmar que la admisión de pruebas obtenidas con violación de derechos fundamentales en un procedimiento vulnera las garantías del debido proceso; mientras que la condena motivada sólo en esas pruebas, vulnera la presunción de inocencia. En este sentido, la obtención de pruebas de manera inconstitucional invalida dichas pruebas, pero no el proceso en su totalidad y, por consiguiente, tampoco una sentencia condenatoria en dicho proceso.

En estas consideraciones el Tribunal Constitucional se aparta de la doctrina del TEDH, que considera que el derecho a no autoincriminarse, íntimamente ligado a la presunción de inocencia ${ }^{66}$, garantiza que la acusación deba aportar pruebas de cargo que no hayan sido obtenidas mediante la coacción al acusado y en contra de su voluntad.

Volviendo a los pronunciamientos del TC, éste ha declarado que los derechos fundamentales no son absolutos sino que están sometidos a ciertos límites, uno de los cuales es la legítima pretensión de persecución y represión de los ilícitos penales. En mérito a un equilibrio entre estos dos valores (derechos fundamentales y persecución penal), los tribunales que deban decidir si el juicio contó con las garantías procesales adecuadas deberán ponderar las diferentes pruebas disponibles a efectos de determinar cuáles de ellas resultan válidas y aptas para destruir la presunción de inocencia. Para ello es necesario determinar si entre la prueba obtenida de manera inconstitucional y el resto de pruebas existe un nexo que permita extender a éstas la ilegitimidad o, en otras palabras, si las pruebas son «jurídicamente independientes». "En la presencia o ausencia de esa conexión reside, pues, la ratio de la interdicción de valoración de las pruebas obtenidas a partir del conocimiento derivado de otras que vulneran el derecho (fundamental)». Esa determinación consiste en una cuestión de hecho que se debe efectuar teniendo en cuenta las circunstancias de cada caso y que no constituye una valoración de la prueba en sí, ni de su virtualidad probatoria de cargo, sino en un análisis del nexo jurídico entre cada prueba y el acto inconstitucional para determinar si queda contaminada por el mismo o es jurídicamente independiente y, por tanto, apta para destruir la presunción de inocencia ${ }^{67}$.

65 STC 57/2013, FJ 6.

${ }^{66}$ Caso Saunders C/Reino Unido, sentencia de 17/12/1996, apartado 68.

67 Por todas, STC 81/1998, FJ 4 y STC 54/2015, FJ 8. 
En la STC 49/1999, el TC luego de declarar nula por violación de la garantía de autoincriminación del art. 24.2 CE a una escucha telefónica realizada sin los presupuestos necesarios, procede a establecer las pautas para que los tribunales ordinarios determinen si la inconstitucionalidad de dicha prueba contamina a las demás, principalmente si existe una "conexión de antijuridicidad» con la prueba declarada inválida, para lo que es necesario examinar, por un lado la índole y características de la vulneración del derecho fundamental (en el caso en concreto, el secreto de las comunicaciones) así como su resultado y, por otro, «las necesidades esenciales de tutela que la realidad y efectividad del derecho... (fundamental) exige», perspectivas que son complementarias pues "sólo si la prueba refleja resulta jurídicamente ajena a la vulneración del derecho y la prohibición de valorarla no viene exigida por las necesidades esenciales de tutela del mismo cabrá entender que su efectiva apreciación es constitucionalmente legitima, al no incidir negativamente sobre ninguno de los aspectos que configuran el contenido del derecho fundamental sustantivo» ${ }^{68}$. Una vez fijados estos cánones, deriva a los tribunales competentes la valoración del resto de la prueba en base a ellos, para determinar si resultan invalidadas por la extensión de la inconstitucionalidad de la escucha y, si no lo están, si son suficientes para destruir la presunción de inocencia.

\section{En la doctrina}

Sanz Díaz-Palacios define el derecho a la no autoincriminación como "el derecho a no confesarse culpable y, como una modalidad cualificada de la misma, el derecho al silencio», así como un derecho de carácter «instrumental» que se ejerce «negándose a responder total o parcialmente a los requerimientos de los poderes públicos» pero «también faltando a la verdad» ${ }^{69} \mathrm{y}$, en su cita de Díez-Picazo Giménez, define su contenido básico como un derecho a «no realizar declaraciones perjudiciales ${ }^{70}$.

Para definir qué es declaración autoinculpatoria y en qué casos estaría protegido por la garantía constitucional, este autor hace

68 STC 49/1999, FJ 14.

${ }^{69}$ SANZ DÍAZ-PALACIOS J.A: Op. Cit, Págs. 53-54.

70 DÍEZ-PICAZO GIMÉNEZ, I: «Artículo 24: Garantias procesales». En ALZAGA VILlAAMIL, O (Dir.): Comentarios a la Constitución Española de 1978, Tomo III, Cortes Generales-EDERSA, Madrid, 1996. Pág. 107. 
una distinción, fundada en abundante doctrina y jurisprudencia, basada en el «material suministrado» por el sujeto investigado ${ }^{71}$ :

a) Por una parte, el «material cuya existencia es independiente de la voluntad del sujeto y contiene una declaración en sí mismo», poniendo como ejemplo «un documento elaborado por terceras personas... que esté en poder del sujeto inspeccionado y que... tenga trascendencia de cara a la determinación de la situación... de dicho sujeto». Este material, entre el cual entendemos incluida la obtención de pruebas físicas del cuerpo del sujeto (como por ejemplo muestras de fluidos corporales para la extracción de $\mathrm{ADN}$, de aire espirado para la prueba de alcoholemia, etc. $)^{72}$ está excluido de la protección constitucional.

b) Por otra parte, el «material cuya existencia depende de la voluntad del sujeto y contiene una declaración en sí mismo. Es éste el caso de las manifestaciones orales o escritas del propio (sujeto). La aportación de esos materiales al órgano inspector (incluida la realización de dichas manifestaciones) constituiría declaración a los efectos del artículo 24.2 del texto constitucional y, por tanto, siendo coactiva esa aportación, nunca tales materiales podrían fundamentar legítimamente la imposición de sanciones... o penas».

Se pueden extraer de las páginas citadas de la obra de Sanz DíazPalacios los elementos que deben estar presentes en el material suministrado para que pueda ser considerado una declaración autoinculpatoria obtenida mediante coacción:

1. Una declaración de voluntad o de conocimiento del sujeto

2. Que sea dependiente de su voluntad

3. Susceptible de autoincriminarlo

4. Cuya aportación sea coactiva

O, como lo resume Palao Taboada ${ }^{73}$ : «Una persona se autoincrimina cuando pone en conocimiento del órgano sancionador informaciones o datos que éste desconocía y no tenía otra manera de averiguar, y en los cuales puede fundarse su sanción o condena».

71 SANZ DÍAZ-PALACIOS, J.A: Op. Cit., págs. 61-64.

${ }^{72}$ Vid PALAO TABOADA, C: El derecho a no inculparse en el ámbito tributario. Thomson-Civitas, Cizur Menor (Navarra), 2008. Págs. 109-111.

${ }^{73}$ Op. Cit, pág. 117. 
Sarró $\mathrm{Riu}^{74}$ apunta que el derecho a no autoincriminarse tiene múltiples fundamentos; entre ellos la garantía de la integridad y fiabilidad de las pruebas proporcionadas por el acusado, la presunción de inocencia y «... la protección de la voluntad del acusado frente a comportamientos abusivos».

Ibáñez ${ }^{75}$ por su parte señala que el derecho a la defensa penal también se puede ver vulnerado por pruebas que en apariencia no son incriminatorias.

La doctrina citada analiza este derecho en el contexto de los procedimientos administrativos y, especialmente, los sancionadores tributarios, poniendo en relación la obligación de todos los ciudadanos de contribuir con el sistema tributario (art. 31.1. CE) de la cual deriva la obligación de colaborar con la inspección de hacienda, con el derecho a la no autoincriminación ${ }^{76}$. Sin embargo en el ámbito tributario no existe una obligación de notificar ciertos hechos, como sí existe en la protección de datos, sino sólo el deber de colaborar con la inspección de hacienda, entregando la documentación o registros que ésta solicite y permitiendo su acceso a locales para la inspección de los registros contables.

En menor medida, la doctrina mercantilista lo analiza en el campo de la defensa de la competencia ${ }^{77}$ en relación con las facultades de inspección de la Comisión Europea para investigar los posibles ilícitos en esta materia, en la que se contrapone el interés de la

74 SARRIÓ RIÚ, J: Op. Cit,. Págs. 50-52.

75 IBÁÑEZ LÓPEZ-POZAS, F: "The charter of fundamental rights of the European Union and the right to defend oneself». Revista de Derecho Político N. ${ }^{\circ}$ 87, mayo-agosto 2013, pág. 95.

${ }_{76}$ Por ejemplo, PALAO TABOADA, C: El derecho a no autoinculparse en el ámbito tributario. Thomson-Civitas, Cizur Menor (Navarra), 2008.; GARCÍA BERRO, F: «La reciente jurisprudencia de ámbito europeo acerca del derecho a no autoincriminarse y sus implicaciones en el procedimiento tributario interno». En Derecho de la Unión Europea y reformas del ordenamiento jurídico español. Servicio de Publicaciones de la Universidad de Huelva, Huelva, 2011. Págs. 117-141; SANZ DÍAZPALACIOS, J.A: Op. Cit.; SANZ DÍAZ-PALACIOS, J.A: «Reflexiones sobre el derecho de las personas jurídicas a no autoincriminarse por delito fiscal en España (Primera Parte)» Análisis Tributario, N. ${ }^{\circ}$ 339, 2016, págs. 24-32; SARRÓ RIÚ, J: El derecho a no autoinculparse del contribuyente. J.M.Bosch Editor, Barcelona, 2009.

77 Por ejemplo, SOTO PINEDA, J.A: «A propósito de un elemento esencial de la defensa de la competencia en Europa: Las facultades de investigación de la Comisión en materia de inspección». Foro, nueva época, vol. 16 N. ${ }^{\circ} 1$ (2013): Págs. 165212. Asimismo: GIL IBÁÑEZ, J.L: «La Comisión y la aplicación del Derecho comunitario de la competencia» en GARRIDO ESPÁ, L: La defensa de la competencia por los órganos judiciales: El Reglamento (CE) 1/2003. Consejo General del Poder Judicial, Madrid, 2005, Pág. 124. 
EL DEBER DE NOTIFICAR Y EL DERECHO A LA NO AUTOINCULPACIÓN...

Unión por la defensa de la competencia y el derecho a la no autoinculpación de las personas jurídicas.

\section{Aplicación al ámbito administrativo}

Uno de los caracteres del Estado moderno es el monopolio del ius puniendi o poder punitivo, que siendo único se manifiesta en dos tipos de potestades punitivas: Por un lado la penal o jurisdiccional, que como su denominación lo indica sólo puede ser ejercida por órganos judiciales penales, en cumplimiento de estrictas reglas procedimentales y cuya expresión máxima es la imposición de penas privativas de la libertad; y por el otro, la potestad sancionadora de la administración pública, que se ejerce asimismo a través de normas de procedimiento administrativo específicas y que tiene vedada la imposición de penas privativas de la libertad, ya sea en forma directa $\mathrm{o}$ indirecta ${ }^{78}$.

Sin perjuicio de la mencionada dualidad, Restrepo Pineda expresa que: "...cualquier tipo de infracción que sea merecedora de un reproche punitivo tiene la misma naturaleza e idénticas consecuencias, pues son expresión del ius puniendi, no obstante que provengan de una autoridad administrativa o jurisdiccional... $\gg^{79}$.

La aplicación de las penas privativas de libertad está sujeta a garantías procesales fundamentales en todo régimen democrático, que en el sistema español tienen su reconocimiento constitucional en los arts. 24 y $25 \mathrm{CE}$. Con respecto a la potestad sancionadora de la administración, este último artículo la introduce como destinataria de alguna de esas garantías, con lo que por un lado la instaura y, por otro, fija algunos de sus límites: El principio de legalidad (art. 25.1 CE) y la imposibilidad de imponer sanciones privativas de libertad (art. 25.3 CE).

Sin perjuicio de que el resto de los derechos y garantías establecidos en los mencionados artículos en su mayoría están concebidos para su aplicación en los procedimientos judiciales, el TC ha manifestado que los principios ordenadores del proceso penal son de aplicación al derecho administrativo sancionador, si bien con algunos

78 Art. 25.3 CE.

79 RESTREPO PINEDA, C.M: «Los principios y garantías del debido proceso penal y su aplicación en materia tributaria». Ratio Juris Vol. 10 n. 20 (enero-junio 2015). Pág. 69. Vid también NIETO, A: Derecho administrativo sancionador. $4 .^{\text {a }}$ edición reimpresa. Tecnos, Madrid, 2006. Págs. 168-169. 
matices ${ }^{80} \mathrm{y}$ "en la medida necesaria para preservar los valores esenciales que se encuentran en la base del (art. 24.2 CE)» siempre que tales garantías sean compatibles con la naturaleza del procedimiento administrativo sancionador ${ }^{81}$.

Al decir de Nieto, "admitida e indiscutida la existencia de la potestad administrativa sancionadora, lo verdaderamente importante es fijar con precisión los límites de su ejercicio» ${ }^{82}$. Algunos de los mencionados límites se encuentran en el art. $25 \mathrm{CE}$, a los cuales la jurisprudencia añade, con matizaciones, algunas de las garantías del art. 24.2 CE. Este autor sostiene que el ordenamiento penal y el ordenamiento administrativo sancionador conforman un único conjunto normativo fraccionado en dos subgrupos a los que se aplican las mismas normas aunque con matices diferentes y basados en el principio de la autonomía normativa y no en el de la jerarquía formal ni en el criterio cronológico. El resultado es que «...las normas reglamentarias del derecho administrativo sancionador no tienen que ceder "necesariamente" ante las normas de rango legal del derecho penal, pero "pueden" ser desplazadas atendiendo a las circunstancias del caso... ${ }^{83}$. Sin perjuicio de lo cual, no existe un criterio general para la aplicación de la garantía o para su matización ${ }^{84}$.

La aplicación de la garantía de no autoincriminación a la potestad sancionadora de la administración pública no está explícitamente reconocida por el derecho positivo aunque sí lo están algunas vinculadas con ella: La Ley 39/15 recoge expresamente la garantía del debido proceso para el procedimiento administrativo común en sus arts. 34.1 y 47.1.e) y f) ${ }^{85}$, y para el procedimiento administrativo sancionador en el art. 63.2; también incorpora la presunción de inocencia para este último procedimiento en el art. 53.2.b) como derecho «A la presunción de no existencia de responsabilidad administra-

${ }^{80}$ NIETO considera las matizaciones del TC como una ingeniosa fórmula con la cual «quedan salvadas las garantías formales, pero se deja abierta la puerta a una aplicación flexible». NIETO, A: Op. Cit, pág. 51.

81 STC 18/1981 FJ 2.

82 NIETO, A: Op. Cit, pág. 89.

83 Ibidem, págs. . 168-169.

${ }^{84}$ Ibidem, pág. 171.

${ }^{85}$ Sin perjuicio de que estos artículos se refieren al procedimiento establecido o legalmente establecido, ya que, a diferencia de los procedimientos judiciales, que están unificados según la materia y establecidos en un único cuerpo legal (Ley de enjuiciamiento civil, ley de enjuiciamiento criminal, ley de la jurisdicción social, etc.), para los procedimientos administrativos existen una gran diversidad de normas procedimentales. Cfr. CARVAJAL, B: «Alcance y limitaciones del debido proceso en el procedimiento administrativo». Revista digital de derecho administrativo, n. ${ }^{\circ} 4$, segundo semestre 2010. Pág. 10 
tiva mientras no se demuestre lo contrario», demostración que deberá realizarse mediante las pruebas admisibles en derecho tal como ya hemos comentado ${ }^{86} \mathrm{y}$ en el marco del debido proceso, que tendrá siempre naturaleza contradictoria y que, en consecuencia, incluye el derecho a la defensa ${ }^{87}$.

La jurisprudencia del TC admite expresamente la aplicación del derecho a no declarar contra sí mismo al derecho administrativo sancionador y, más específicamente, al ámbito tributario ${ }^{88}$, habiendo expresado que "Este reconocimiento del derecho a no declarar contra sí mismo, en cuanto garantía instrumental del derecho de defensa, ha de ser respetado, en principio, en la imposición de cualesquiera sanciones administrativas, sin perjuicio de las modulaciones que pudiera experimentar en razón de las diferencias existentes ente el orden penal y el administrativo sancionador» ${ }^{89}$.

Ha admitido asimismo la aplicación al ámbito administrativo sancionador del derecho a la presunción de inocencia y la prohibición de valoración de pruebas obtenidas con vulneración de derechos fundamentales ${ }^{90}$, todas ellas manifestaciones del derecho a la defensa que, a su vez, es una parte esencial del debido proceso en sede administrativa ${ }^{91}$. Pero estas manifestaciones no son de aplicación automática e incondicional, sino que en cada caso se deben examinar todas las circunstancias presentes para decidir hasta qué grado resultan aplicables o, en otras palabras, si es necesario matizarlas.

Por otra parte, el Tribunal Europeo de Derechos Humanos también viene sosteniendo desde hace algunos años ${ }^{92}$ que los principios procesales contenidos en el art. 6 del CEDH se aplican a todos los delitos sin excepción; pero también se aplican a las investigaciones

${ }^{86}$ En el Cap. II apartado A.

87 REBOLLO PUIG, M; IZQUIERDO CARRASCO, M. y otros: «Panorama del derecho administrativo sancionador en España». En Estudios Socio-Jurídicos, vol. 7 n. ${ }^{\circ}$ 1, enero-junio 2005. Pág. 40

${ }_{88}$ Entre otras a través de la STC 272/2006, FJ 3.

89 STC 54/2015, de 16 de marzo, FJ 7.

${ }^{90}$ Entre otras, STC 7/1998, FJ 5, STC 142/2009, FJ 4 y jurisprudencia citada.

${ }^{91}$ RUOCCO, G: "El principio del "debido proceso" en vía administrativa». Revista de Direitos Fundamentais e Democracia, V 13 n. ${ }^{\circ}$ 13, enero-junio 2013. Pág. 3. Para este autor, la garantía del debido proceso en sede administrativa tiene un carácter instrumental doble: «en cuanto opera como garantía de la defensa, que no vale por sí, sino por los derechos e intereses sustanciales agredidos o eventualmente lesionados; y también respecto la eficiencia administrativa, ya que el conocimiento previo de las razones del destinatario de su accionar coadyuva a su legalidad, conveniencia y oportunidad».

${ }^{92}$ Por todos, Caso Saunders. 
no judiciales, especialmente si en ellas se obtienen pruebas que puedan ser utilizadas para incriminar al acusado en un posterior juicio penal, y que el interés público no tiene la suficiente entidad como para dar validez a esas pruebas ${ }^{93}$. Considera asimismo extensible la aplicación de la garantía de no autoincriminación a los procedimientos administrativos ${ }^{94}$ y se decanta por interpretar la expresión de «acusación en materia penal» del art. 6.1 CEDH en un sentido material y no formal, considerando equivalente a una persecución penal las expresiones tales como contravención e infracción y la presencia de una amenaza de sanción, y sostiene que el derecho a la no autoincriminación se puede invocar antes e incluso en ausencia de procedimiento sancionador ${ }^{95}$.

En este sentido, las multas administrativas establecidas en el art. 83 RGPD constituyen, sin ningún tipo de dudas, manifestación del ius puniendi y, por lo tanto, se justifica en ellas la aplicación de las garantías constitucionales del procedimiento penal ${ }^{96}$.

Sin embargo, en cuanto a los poderes correctivos ${ }^{97}$ establecidos en el art. 58.2 RGPD, nos inclinamos por considerar a las advertencias y apercibimientos de naturaleza no penal y, en consecuencia, no protegidas por estas garantías ${ }^{98}$. En cuanto a otras facultades como las órdenes de hacer o no hacer, limitaciones a los tratamientos, retirada de una certificación o la orden de suspensión de los flujos de datos hacia un tercer país u organización internacional, consideramos que dependerá de las circunstancias del caso si pueden ser consideradas manifestaciones del ius puniendi del Estado o serán sim-

93 Caso Saunders, apartado 74.

${ }^{94}$ Caso Saunders, apartado 67 y caso Deweer c/Bélgica, sentencia de 27/02/1980, apartados 41 a 47.

${ }_{95}$ Caso Shannon C/Reino Unido, sentencia de 04/10/2005, apartados 34 y 35 y jurisprudencia citada.

96 REBOLLO PUIG, M; IZQUIERdo CARRASCO, M. y otros: Op. Cit. Pág. 24.

$97 \mathrm{El}$ art. 58.2 RGPD da el nombre genérico de poderes correctivos a las facultades que otorga a continuación a las APD, que tal como exponemos en estos párrafos, a algunas de ellas las consideramos verdaderas sanciones o penas mientras que otras no pasan de simples y verdaderas correcciones, mientras que otras pueden tener una u otra naturaleza, lo que dependerá de las circunstancias del caso.

98 Como bien señala CORRAL SASTRE, las autoridades de protección de datos están facultadas para imponer la sanción mediante advertencias cuando «... las operaciones de tratamiento previstas puedan infringir lo dispuesto en el presente Reglamento» (art. 58.2.a RGPD, el subrayado en negrita es nuestro), es decir que para este tipo de corrección no se exige ningún grado de certeza ni la desvirtuación de la presunción de inocencia como sí ocurre para el resto de sanciones. CORRAL SASTRE, A: «XXXI. El régimen sancionador en materia de protección de datos en el Reglamento General de la Unión Europea». En PIÑAR MAÑAS, J.L: Reglamento General de Protección de Datos... cit, pág. 583. 
ples correcciones, lo que puede depender en gran medida de si se les otorga carácter provisional o, en otras palabras, si el incumplimiento puede ser subsanado por el responsable. Si la sanción es definitiva, consideramos que en algunos casos puede llegar a tener la misma entidad que las establecidas en el art. 33.7 del Código Penal ${ }^{99}$ $\mathrm{y}$, por lo tanto, tener naturaleza punitiva.

\section{CONCLUSIONES}

I. La protección de los datos personales ante una manipulación indebida es un derecho fundamental reconocido en los ordenamientos jurídicos tanto europeo como español, lo que obliga al derecho público de estos niveles a disponer las medidas necesarias para garantizar su respeto, tanto por parte de los particulares como de las entidades públicas. Con este objetivo, el RGPD implanta un modelo de protección de datos que incluye, entre otros elementos, principios que los tratamientos deben respetar, derechos de los interesados y, fundamentalmente en lo que a esta investigación interesa, obligaciones que deben cumplir los responsables y encargados de los tratamientos. Entre esas obligaciones se encuentra la de garantizar la seguridad de los datos personales que están sometiendo a tratamiento, ya que una violación o brecha de la mencionada seguridad pone en riesgo los derechos y libertades de las personas, en medida variable dependiendo de las circunstancias del caso.

II. Sin perjuicio de dicha obligación, cuando tiene lugar una brecha de seguridad, el RGPD pone a cargo de responsables y encargados del tratamiento de datos personales la obligación de notificarla a la APD si ha afectado a los datos que tratan; notificación que permitirá a las referidas autoridades y, en su caso, a los interesados, adoptar las medidas pertinentes para disminuir en lo posible los resultados nocivos que la manipulación indeseada de los datos personales pueda suponer para su vida privada, su honor, su personalidad u otros bienes jurídicos, efectos que pueden ser sumamente perjudiciales cuando los datos tratados son los especialmente protegidos del art. 9 RGPD u otros datos sensibles. La comunicación de las violaciones de seguridad se convierte así en una herramienta de suma importancia

${ }^{99}$ Artículo que establece las penas que se pueden imponer a las personas jurídicas, que pueden ir desde multas hasta su disolución, pasando por la clausura de sus locales y establecimientos, suspensión de actividades, inhabilitaciones e intervención judicial. 
en la protección de los derechos fundamentales de las personas, por ello el RGPD coacciona a los responsables y encargados del tratamiento con la imposición de sanciones administrativas en caso de incumplimiento.

III. Las facultades y poderes de investigación, de corrección y sancionadores que el derecho europeo y nacional otorgan a las APD conceden a éstas mayor eficacia e independencia en su actuación, al posibilitarles el acceso a más información, datos y documentos que les permitirán tomar conocimiento de hechos y circunstancias que vulneren las disposiciones del RGPD a efectos de adoptar las medidas necesarias para corregirlos, así como recabar evidencia y sancionar a sus responsables. Por todo ello los referidos poderes y facultades, sin los cuales gran parte de esa actuación sería imposible, son también herramientas indispensables para la protección de los derechos y libertades de los individuos, finalidad principal de la actividad de las APD.

IV. Pero en muchas ocasiones las disposiciones de regulación y protección de los datos personales colisionan con otros derechos y libertades, como la libertad de circulación de los datos, el derecho a la información, la libertad de expresión, etc. Dado que la protección de datos personales no es un derecho absoluto, en estos casos, el legislador a nivel general y las autoridades administrativas y judiciales en los casos concretos, deben ponderar cada uno de los derechos y libertades en liza para encontrar una solución justa y respetuosa con los valores involucrados.

V. En este orden de ideas, la obligación de comunicación de las brechas de seguridad impuesta en el artículo 33.1 del RGPD para responsables y encargados del tratamiento genera por parte de éstos una declaración que, en ocasiones, puede llegar a ser autoincriminatoria al dejar al descubierto que quien la cursa ha incurrido en uno o más incumplimientos de las obligaciones a su cargo, o éstos pueden ponerse en evidencia durante la investigación que sobre la brecha realice la APD. Este tipo de declaraciones, al ser obtenida por la APD bajo la coacción que implica la amenaza de la sanción impuesta por el RGPD para los incumplimientos de las obligaciones a cargo de responsables o encargados, se obtiene con vulneración de su derecho a la no autoinculpación.

VI. Tal como hemos sostenido durante el desarrollo de este trabajo y en los párrafos precedentes, la obligación de notificación del art. 33.1 es una herramienta valiosa para el ejercicio de las fun- 
ciones de la APD y para la protección de los datos personales en general, por lo tanto el hecho de que se convierta en una declaración autoinculpatoria obtenida bajo coacción no implica que sea inconstitucional ni la necesidad de su prohibición, sino otro tipo de soluciones que permitan lograr un equilibrio entre los valores en colisión: Por un lado la necesidad de ese tipo de notificaciones para la protección de los datos personales y, por el otro, el derecho a la no autoinculpación de responsables y encargados, derecho que por otra parte no se vulnera con el hecho de la notificación en sí, sino con la utilización de la notificación como prueba de cargo contra su emisor en un procedimiento sancionador. Esa colisión de valores se observa también en la doctrina que hemos analizado sobre el derecho a la no autoincriminación, que contrapone este valor con la obligación de todos los ciudadanos de contribuir con el sistema impositivo en la doctrina tributaria y con el control del derecho a la competencia, en la doctrina mercantilista.

VII. Las disposiciones legales analizadas en el Capítulo II, apartado B.1), declaran la inadmisibilidad de un elemento probatorio obtenido mediante vulneración de los derechos fundamentales (como puede ser una declaración autoinculpatoria obtenida mediante coacción) o, en otras palabras, despojan al elemento de su virtualidad probatoria. Y, conforme a las construcciones doctrinales que hemos resumido en el Capítulo II apartado B.3), la notificación de una violación de seguridad, si contiene la comunicación de un incumplimiento de las obligaciones a cargo del emisor, puede reunir las condiciones necesarias para constituir una declaración autoinculpatoria obtenida bajo coacción y, como tal, ser inadmisible como prueba en un procedimiento sancionador contra quien la ha realizado.

VIII. La declaración autoinculpatoria surgida de la notificación de una brecha de seguridad también podría vulnerar el art. 6 CEDH según la jurisprudencia del TEDH, y su utilización en un procedimiento sancionador podría acarrear la nulidad de éste. Si bien todo ello debe ser evaluado por el órgano judicial competente, quien deberá ponderar, entre otras cosas, el grado de coacción (la multa o corrección a la que está sometido el incumplimiento de las obligaciones implicadas), el grado de incumplimiento descubierto mediante la notificación y el interés público implicado, es decir, el grado en que todas estas circunstancias afectan al derecho a la protección de datos personales de los interesados, y sus consecuencias. También se deberían analizar 
otras circunstancias atinentes al procedimiento, en especial el resto de la evidencia, la conducta posterior del declarante y los demás valores y derechos fundamentales implicados.

IX. El TJUE, si bien se ha pronunciado en muchas oportunidades sobre el derecho a la protección de datos, no cuenta con una doctrina consistente respecto al derecho a la no autoinculpación, lo que se debe sin duda a que no es un órgano de naturaleza exclusivamente constitucional.

X. En el plano interno español, como ya hemos adelantado, la invalidez de una prueba obtenida con vulneración de un derecho fundamental también debe ser declarada por el órgano judicial. Así, ante la revisión en sede jurisdiccional de la utilización de la notificación realizada por un responsable de un tratamiento como prueba en su contra para la imposición de una sanción se podría declarar vulnerado el derecho de no autoincriminación (que es parte del derecho a un proceso con todas las garantías), en virtud de lo cual esa declaración y todas las restantes constancias que estén conectadas con ésta de tal forma que se puedan considerar contaminadas por la inconstitucionalidad pueden ser anuladas como pruebas de cargo, pero esto por sí solo no atenta contra la presunción de inocencia ni implica la anulación del juicio.

XI. Ahora bien, al analizar la vulneración del derecho a la no autoincriminación el Tribunal deberá evaluar las circunstancias mencionadas en el párrafo VIII precedente, de entre las cuales destacamos la gravedad de los incumplimientos que la notificación deja al descubierto, ya que si sólo merecen una corrección (por ejemplo un apercibimiento o advertencia), al no tener naturaleza sancionadora su comunicación a la APD no se considerará autoincriminación. Cuando en virtud de los motivos expresados en el párrafo precedente el TC declare la inadmisibilidad de una notificación como prueba de cargo y se extienda la misma a una o más pruebas por haber sido obtenidas con vulneración de un derecho constitucional, corresponderá al tribunal de instancia volver a evaluar las pruebas subsistentes a efectos de decidir si son suficientes para destruir la presunción de inocencia y, en caso de que no lo sean, corresponderá la absolución del acusado.

XII. Las reglas sentadas en los párrafos precedentes fueron concebidas para las sanciones penales, sin perjuicio de lo cual se ha extendido su aplicación también al ámbito administrativo, aun- 
que con matizaciones para las cuales no existen reglas predeterminadas sino que deben ser decididas en cada caso concreto. El hecho de que no existan reglas preestablecidas para las matizaciones de adaptación implica, por un lado, que los órganos jurisdiccionales no están ceñidos a precepto alguno sino que gozan de libertad para decidir sobre ellas; pero por otro, que las mentadas matizaciones deben estar suficientemente motivadas para no caer en la arbitrariedad.

XIII. En resumen, ante la notificación a la APD de una violación de la seguridad de los datos personales por parte de un responsable o de un encargado de los tratamientos se deberá evaluar si ésta implica su autoinculpación sobre el incumplimiento de las obligaciones impuestas por el RGPD, en cuyo caso su utilización como prueba contra el notificante en un posterior procedimiento sancionador puede ser nula por vulneración del derecho a no declarar contra sí mismo. Invalidez que podría transferirse al resto de evidencias que recabe la APD en base al conocimiento adquirido por medio de la notificación de la brecha de seguridad, a menos que éstas puedan ser halladas jurídicamente independientes de la notificación.

XIV. La protección constitucional se refiere a la declaración autoinculpatoria, que podrá existir sólo cuando el responsable notifica a la APD una violación de la seguridad. En los casos en que la APD tome conocimiento de una brecha de seguridad que no le ha sido notificada e inicie una investigación, las pruebas así recabadas no estarán cubiertas por la protección del art. 24.2 de la $\mathrm{CE}$, por lo que tendrán plena validez para ser utilizadas en un procedimiento sancionador.

\section{BIBLIOGRAFÍA}

Arenas Ramiro, M: El derecho fundamental a la protección de datos personales en Europa. Tirant lo Blanch, Valencia, 2006.

CARVAJAL, B: «Alcance y limitaciones del debido proceso en el procedimiento administrativo". Revista digital de derecho administrativo, n. ${ }^{\circ}$, segundo semestre 2010. Págs. $7-21$.

Chulvi Pauner, C: «Implicaciones del futuro reglamento europeo sobre protección de datos en la libertad de información». En Los derechos a la intimidad y a la privacidad en el Siglo XXI. Ed. Dykinson, Madrid, 2015. 
Díez-Picazo Giménez, I: «Artículo 24: Garantías procesales». En ALZAGA ViLlaAmiL, O (Dir.): Comentarios a la Constitución Española de 1978, Tomo III, Cortes Generales-EDERSA, Madrid, 1996.

GARCÍA BERRO, F: «La reciente jurisprudencia de ámbito europeo acerca del derecho a no atoincriminarse y sus implicaciones en el procedimiento tributario interno". En Derecho de la Unión Europea y reformas del ordenamiento jurídico español. Servicio de Publicaciones de la Universidad de Huelva, Huelva, 2011. Págs. 117-141.

GIL IBÁÑEZ, J.L: «La Comisión y la aplicación del Derecho comunitario de la competencia» en Garrido Espá, L: La defensa de la competencia por los órganos judiciales: El Reglamento (CE) 1/2003. Consejo General del Poder Judicial, Madrid, 2005, Pág. 124.

GÓMEZ GARRIDO, J: «Derecho al honor y persona jurídica-privada». REDUR 8, diciembre 2010, págs. 205-225.

Gómez SÁnchez, Y: Constitucionalismo multinivel. Derechos fundamentales. Ed. Sanz y Torres, Madrid, 2015

HiRsch, D: "The Glass House Effect: Big data, the new oil, and the power of analogy». Maine Law Review, Volumen 66 N. 2 (2014).

IBÁÑEz LóPEz-PozAS, F: «The charter of fundamental rights of the European Union and the right to defend oneself». Revista de Derecho Político, N. ${ }^{\circ}$ 87, mayo-agosto 2013, Págs. 77-100.

LEÓN JIMÉNEZ, R: «Los derechos fundamentales de las empresas en el procedimiento de competencia comunitario». En ORTIZ BLANCO, L. y Pascual Sequeiros, A. (Coords.): Derecho de la competencia europeo y español, vol. III. Ed. Dykinson, Madrid, 2002, págs. 115 y ss.

LóPEz Guerra, L: «El Tribunal Europeo de Derechos Humanos, el Tribunal de Justicia de la UE y "le mouvement nécessaire des choses"». Teoría y Realidad Constitucional, N. ${ }^{\circ}$ 39, 2017, págs. 163188.

LÓPez RomÁn, E. y Mora, J.S: «Un análisis de la estructura institucional de protección de datos en España». InDret: Revista para el análisis del derecho, 2/2009.

LORENTE LóPEZ, M.C: «Los derechos al honor, a la intimidad personal y familiar y a la propia imagen en la jurisprudencia más reciente». En Los derechos a la intimidad y a la privacidad en el Siglo XXI. Ed. Dykinson, Madrid, 2015, págs. 131-155.

Martín y Pérez de Nanclares, J: «El TJUE como actor de la constitucionalidad en el espacio jurídico europeo: La importancia del 
EL DEBER DE NOTIFICAR Y EL DERECHO A LA NO AUTOINCULPACIÓN...

diálogo judicial leal con los tribunales constitucionales y con el TEDH». Teoría y realidad constitucional, N. ${ }^{\circ}$ 39, 2017. Págs. 235269.

MAyor Gómez, R: «Contenido y novedades del Reglamento General de Protección de Datos de la UE (Reglamento UE 2016/679, de 27 de abril de 2016». Gabilex, N. ${ }^{\circ}$ 6, junio 2016. Págs. 243-280.

Murillo De la Cueva, P.L: El derecho a la autodeterminación informativa. Fundación Coloquio Jurídico Europeo, Madrid, 2009.

NiETo, Alejandro: Derecho administrativo sancionador. 4. ${ }^{a}$ edición reimpresa. Tecnos, Madrid, 2006.

Ortega Giménez, A. y Gonzalo Domenech, J.J: «Nuevo marco jurídico en materia de protección de datos de carácter personal en la Unión Europea». Revista de la Facultad de Derecho de la Universidad de la República (Montevideo), N. ${ }^{\circ}$ 44, ene-jun 2018. Págs. 63-97.

Palao Taboada, C: El derecho a no autoinculparse en el ámbito tributario. Thomson-Civitas, Cizur Menor (Navarra), 2008.

Piñar Mañas, J.L (Dir.): Reglamento General de Protección de Datos. Hacia un nuevo modelo europeo de privacidad. Ed. Reus, Madrid, 2016.

Punset Blanco, R: «Derechos fundamentales y primacía del derecho europeo antes y después del caso Melloni». Teoría y Realidad Constitucional, N. ${ }^{\circ}$ 39, 2017. Págs. 189-212.

Rebollo Delgado, L.: Derecho constitucional I. 3. a ed. Ed. Dykinson, Madrid: 2017.

Rebollo Delgado, L.: El derecho fundamental a la intimidad. 2. ed. Ed. Dykinson, Madrid: 2005

Rebollo Delgado, L: Protección de datos en Europa. Origen, evolución y regulación actual. Ed. Dykinson, Madrid, 2018

Rebollo Delgado, L: «Veinticinco años de relación entre la informática y los derechos al honor y a la intimidad personal y familiar». Revista de Derecho Político, N. . 58-59 (2003-2004). Págs. 215-239.

Rebollo Puig, M; IzQuierdo Carrasco, M. y otros: «Panorama del derecho administrativo sancionador en España». En Estudios SocioJurídicos, vol. 7 n. ${ }^{\circ}$ 1, enero-junio 2005. Págs. 23-74. 
RestrePo Pineda, C.M: «Los principios y garantías del debido proceso penal y su aplicación en materia tributaria». Ratio Juris Vol. 10 n. ${ }^{\circ} 20$ (enero-junio 2015). Págs. 61-86.

SAnz Díaz-Palacios, J.A: Derecho a no autoinculparse y delitos contra la Hacienda Pública, Colex, Madrid, 2004;

SAnz Díaz-Palacios, J.A: «Reflexiones sobre el derecho de las personas jurídicas a no autoincriminarse por delito fiscal en España (Primera Parte)» Análisis Tributario, N. ${ }^{\circ}$ 339, 2016, págs. 24-32

Sanz Díaz-Palacios, J.A: «Reflexiones sobre el derecho de las personas jurídicas a no autoincriminarse por delito fiscal en España (Segunda Parte)». Informe Tributario, N. ${ }^{\circ} 299,2016$, págs. 6-10

SARRó RIU, J: El derecho a no autoinculparse del contribuyente. J.M.Bosch Editor, Barcelona, 2009.

Soto PinedA, J.A: "A propósito de un elemento esencial de la defensa de la competencia en Europa: Las facultades de investigación de la Comisión en materia de inspección». Foro, nueva época, vol. 16 N. ${ }^{\circ} 1$ (2013): Págs. 165-212.

Troncoso ReigadA, A: «Las redes sociales a la luz de la propuesta de reglamento general de protección de datos personales. Parte una». En «Retos y oportunidades del entretenimiento en Línea» [monográfico en línea]. IDP. Revista de Internet, Derecho y Política. N. ${ }^{\circ} 15$, págs. 61-75. UOC.

Troncoso Reigada, A: «Las redes sociales a la luz de la propuesta de reglamento general de protección de datos personales. Parte dos». Revista de Internet, Derecho y Política. N. ${ }^{\circ}$ 16, pág. 27-39. UOC.

UGARTEMENDIA ECEIZABARRENA, J.I: «La eficacia entre particulares de la Carta de Derechos Fundamentales de la Unión Europea a la luz de la jurisprudencia del Tribunal de Justicia» Teoría y Realidad Constitucional, N. ${ }^{\circ}$ 39, págs. 361-366.

Veleiro ReBOREDo, B: Protección de datos de carácter personal y sociedad de la información. Boletín Oficial del Estado, Madrid, 2008. 